\title{
TELEJORNALISMO, ÉTICA E CIDADANIA ${ }^{1}$
}

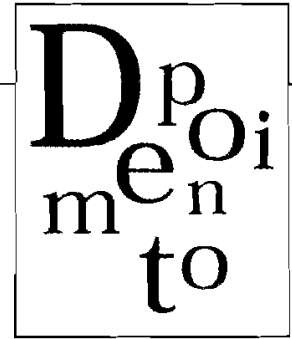

\section{Jornalismo requer postura ética e compromisso com seu tempo na construção da informação para a mudança da realidade}

A nossa profissão começa na hora em que você abre o olho e liga tudo outra vez. Começo de manhã ouvindo rádio, fazendo barba. Tomo café da manhã olhando o jornal. No carro, estou ouvindo rádio: $C B N$, Eldorado, Bandeirantes, Jovem Pan. Estou preso no trânsito mas estou me informando. Chego na televisão, vou abrindo o terminal de computador para ver o que as agências estão noticiando, o que o nosso jornal está dando, o que foi noticiado nos telejornais da manhã. Vou me informando o tempo todo. Fazemos o telejornal e quando ele termina, temos reunião, discutimos, pegamos o telefone e conversamos com um, trocamos idéia com outro. Quando chego em casa, 18, 19 horas, ligo a TV para ver os telejornais locais. Assisto ao Jornal Nacional, ao Boris Casoy. No intervalo, vejo o Jornal da Bandeirantes, depois o Globo News. Quando minha mulher chega, conversamos sobre o que aconteceu durante o dia, que matéria ela estava fazendo etc.

Um dia, falando com uma repórter de uma revista, que faz perfil de quem trabalha na televisão, ela me perguntou sobre como é a minha vida pessoal. Então, disse a ela que estava justamente falando da minha vida pessoal. A minha vida pessoal é isso tudo, a minha semana não começa na sexta-feira para terminar no domingo à noite. Começa na segunda-feira e vai até a outra segunda-feira. E se o jornalista não for capaz de encontrar nisso satisfação, alegria, sentido, então ele tem que trabalhar em outra coisa. Ou o jornalista se envolve absolutamente com o seu trabalho ou não. Não há lugar nessa profissão para quem não tiver esse tipo de perfil. Quem não for assim não dá para ser jornalista. É possível viver com esse nível de envolvimento. O Jornalismo é uma profissão profundamente filosófica. A todo momento se está perguntando sobre o

\section{O AUTOR}

\section{Chico Pinheiro}

Jornalista, âncora do telejornal SPTV, da Rede Globo.

1. Depoimento transcrito de palestra realizada no curso de pós-graduação lato sensu Gestão de Processos Comunicacionais, na Escola de Comunicações e Artes da USP, em 12 de novembro de 1998. 
sentido profundo da vida, da razão de ser do seu trabalho. A todo momento o profissional está se reconhecendo como aquele que fabrica, aquele que constrói.

Lembro-me de que o pessoal que fez curso científico (segundo grau) comigo, na hora de fazer a faculdade se dividiu em dois e meio: uma parte foi fazer Engenharia, outra parte foi fazer Medicina e alguns foram fazer Direito. Naquela época, existia uma falsa idéia de quem fazia Jornalismo, História, Sociologia, Filosofia eram os jovens que não davam conta do vestibular. Jornalismo, pensava-se, era coisa para gente que não quer saber de dureza, boêmio. Fui parar na Engenharia Civil, na Universidade Federal de Minas Gerais. Cheguei a fazer quatro anos de Engenharia, depois percebi que não dava para mim. Mas fazia Engenharia e fazia Jornalismo. Estudava Engenharia de manhã e Jornalismo à noite. Observava que a turma de Jornalismo era um negócio maluco, fervia, pegava fogo. Na Engenharia o pessoal estava de manhã cada um no seu cantinho. Pareciam dois mundos absolutamente diferentes. De noite, ninguém estava preocupado com a prova no fim do mês. Estavam todos preocupados com o que estava acontecendo naquele momento.

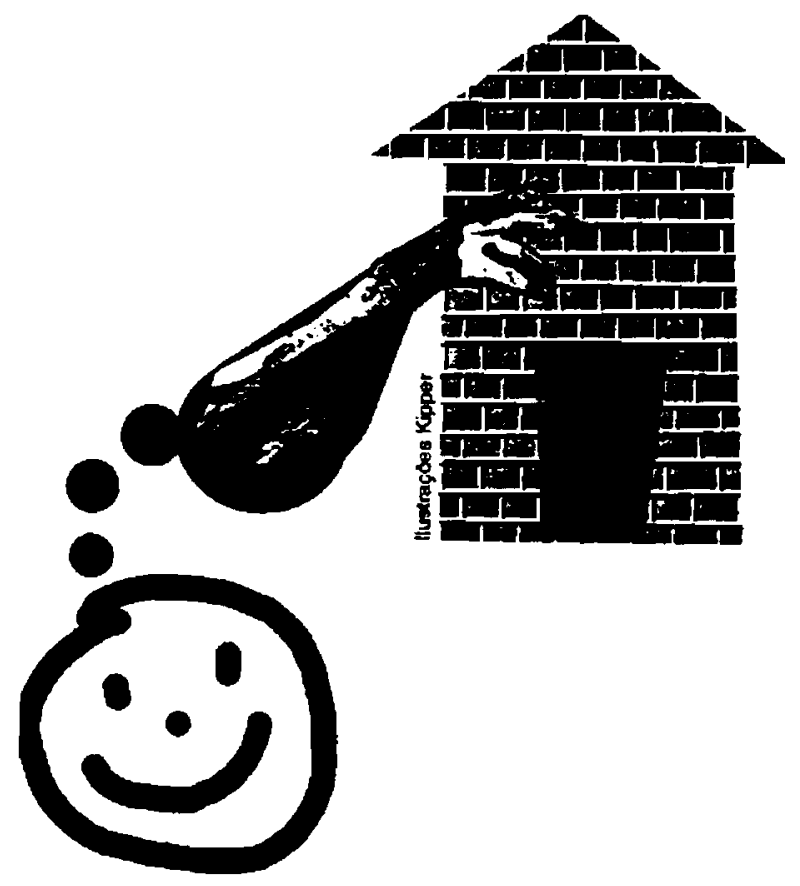

As pessoas que buscavam o Jornalismo, buscavam com essa vontade, essa coisa do sonho, de vamos fazer. Ninguém entrava no curso de Comunicação e pensava em trabalhar na televisão. Nunca 
pensei em trabalhar em televisão, achava tudo isso uma grande bobagem. Jornalista de televisão era incipiente. Pensava trabalhar em jornal, nem em jornal, queria mesmo era ser jornalista, onde iria trabalhar era outra história. Todos queríamos trabalhar com os fatos, ser repórter, reportar os acontecimentos. Por fim, comecei trabalhando em jornal, depois é que fui para a televisão e descobri que ela é uma coisa fantástica, sobretudo num país como o Brasil, onde as pessoas não podem sequer comprar jornal, e a televisão passa a ter importância como um veículo de informação e de educação.

Na Europa a televisão chegou após um século de experiência de leitura de jornais. Chegou para uma população crítica, uma população que lê, que discute. No Brasil acontece o contrário, a televisão chega antes do jornal, embora o jornal já exista há muito tempo, mas as grandes massas não têm acesso a essa informação escrita. Então, a responsabilidade passa a ser maior. Retomando, quando naquele momento queríamos fazer Jornalismo, queríamos ser repórter, a discussão sobre ética não estava tão explícita quanto hoje, mas o sentido estava muito nítido. Dez anos depois que saí da universidade, faço um concurso para ser professor, deixo a televisão para dar aulas de Jornalismo e encontro um universo de alunos completamente diferente do meu tempo.

\section{ÉTICA E PERFIL DO JORNALISTA}

Um pessoal mais comportado, mais objetivo, mais pragmático. Um pessoal que está de olho no mercado. No curso de Jornalismo, encontro um monte de menininhas bonitinhas, de rapazes bem arrumados e começo a ver que há outros fatores motivando a demanda por esse curso. Começo a ver que a televisão já reina com muita força. As pessoas que querem ser famosas mas não têm talento para ser ator, atriz, nem cantor, nem modelo, colocamse a possibilidade de ser repórter da TV Globo ou apresentador de televisão. Ou seja, as pessoas estão querendo aparecer.

Não quero generalizar essa crítica, mas vi isso e vi anos seguidos e vejo hoje ainda. As pessoas não sabem bem por que estão indo para o Jornalismo. Têm uma idéia de que se paga bem, mas não é bem assim. Os salários que são mostrados na imprensa são os salários de algumas pessoas. A maioria dos profissionais do Jornalismo trabalham muito para acertar seu orçamento no fim do mês e se sustentar na profissão. Se continuam é porque são apaixonados pelo Jornalismo, porque ainda crêem em utopia. São esses que se envolvem com a notícia o tempo todo. Então, há muita gente procu- 
rando o curso de Jornalismo pensando no mercado, pensando na oportunidade de aparecer. Mas, muita gente também que está buscando o jornalismo para mostrar o seu trabalho, a sua capacidade, o seu compromisso com o seu tempo, com a história, com seu país. Mas há uma mudança já de perfil, sem dúvida. Nesse momento passa a ser muito importante a discussão sobre a ética e até uma discussão anterior à ética. Porque se a ética é um estudo da conduta, me interessa o sentido dessa conduta. Quero tocar na questão moral, para que serve a ética?

É aí que começo a pensar sobre o sentido da informação que constrói a cidadania. Essa palavra está ficando gasta, mas não tenho outra. Pensar na necessidade da informação que permita ao telespectador a consciência crítica da realidade que o cerca, ou seja, como os fatos que acontecem mexem com a sua vida, com a vida da sua comunidade. Como os fatos da sua cidade interferem no seu dia-a-dia. Como os fatos de seu país e do planeta interferem no seu cotidiano e de que maneira interferem.

Esse telespectador, tendo consciência da interferência dos fatos na sua vida, pode, em comunidade, trabalhar pela superação desse quadro de injustiça, de contradições que se vê. Ele poderá transformar essa realidade, sua vivência diária. A informação que permite clareza dessa consciência pode gerar uma ação. É essa a informação que me interessa muito. $O$ resto você vai atender às necessidades do Ibope e pode, inclusive, estar fazendo mal às pessoas que vivem imersas na violência e que vão acordar às sete horas da manhã e dar de cara com um crime. A informação sobre violência já está aí, e as pessoas já têm consciência disso, vai ser um dado a mais. Então, vou procurar trabalhar o fato da violência nas suas raízes mais profundas, no contexto social, econômico. Os números da violência aí sim podem permitir uma reflexão sobre a violência.

A missão da televisão e do telejornalismo é nobre em um país onde há falta de informação e de absorção crítica dessa informação. Tem a função de trazer informação que permita a discussão, que construa a consciência crítica do cidadão. Acho que esse é nosso papel.

A televisão tem resgatado a realidade que estava e esteve escondida, por vários motivos, da maior parte da sociedade brasileira. Ou não se sabia que a polícia sempre espancou e matou? O Brasil inteiro sabe disso. A televisão tem resgatado essas imagens das sombras para a luz. Essas imagens obrigam a sociedade, os poderes constituídos, às mudanças. A televisão tem resgatado a possibilidade de avanço da democracia no país, de consolidação da democracia. 
A nossa missão tem também muito de educação. Acaba-se sendo um pouco educador quando se está na televisão. A televisão educa, quando coloca a sociedade se discutindo no ar, ao vivo. Traz à luz as informações que sempre estiveram relegadas à sombra. Essa sombra que garante ou que garantiu a impunidade e a perpetuação de um modelo de injustiça no país.

Agora é evidente que há uma parcela de responsabilidade dos meios de comunicação nesse processo que se viveu até pouco tempo. Por isso vou dizer que a televisão mudou. Mudou porque o Brasil tem mudado. A sociedade tem mudado e não consigo aceitar a idéia de que a televisão faz a cabeça do brasileiro. Acho que são as duas coisas, porque vi a televisão, ainda forçada pelo regime militar, não se sentir em condições de cobrir as Diretas Já e vi a televisão entrar na cobertura forçada pela sociedade, quem viveu se lembra disso. A pressão da sociedade e o avanço democrático, o avanço a partir da participação da sociedade. Há uma interação entre sociedade e meios de comunicação que vai transformando a realidade. Quanto mais exigente vai ficando a sociedade, quanto mais liberdade se exercita, mais pode aumentar a mudança.

Por isso, vejo com grande esperança o trabalho que realizamos no SPTV. Essa nova maneira de trabalhar a informação comunitária. Pois, é na comunidade que ocorrem as grandes contradições do país. É fascinante conviver com essa evolução. A contestação que muitos dizem existir com relação ao trabalho da TV Globo é fundamental para o nosso trabalho. Essa contestação permite a reflexão, permite a avaliação do que fizemos e é fundamental para alargar o espaço de liberdade nos meios de comunicação.

Resumo: Chico Pinheiro trata do perfil do jornalista, ressalta a necessidade do envolvimento profissional e o compromisso ético e histórico do jornalista com a transformação da realidade de injustiças sociais. Ressalta a importância do acesso à informaçāo para que se possa conhecer e agir sobre a realidade. Vê o jornalismo como construtor da cidadania.

Palavras-chave: Chico Pinheiro, jornalismo, ética, cidadania, perfil profissional
Abstract: Chico Pinheiro deals with the profile of the journalist, stressing the need for professional involvement, and elaborates on the ethical and historical commitment journalists have with transforming social injustice realities. He emphasizes the importance of one's having access to information in order for the person to know and act on reality. Pinheiro sees journalism as a constructor of citizenship.

Key words: Chico Pinheiro, journalism, ethics, citizenship, professional profile 